\title{
Early Neonatal Outcomes in Premature Rupture of Membranes Beyond Twenty-eight Weeks of Gestation in a Tertiary Care Hospital of Coastal Karnataka
}

\author{
(1) Sweta Shanbhag, (1) Rashmi Alva \\ Father Muller Medical College, Department of Pediatrics, Mangalore, India
}

\begin{abstract}
Aim: Premature rupture of membranes (PROM) is a significant risk factor for various adverse neonatal outcomes such as prematurity, respiratory distress, birth asphyxia and early onset neonatal sepsis. Due to the public health relevance of this topic and its higher burden on health care services, this study was carried out to the identify risk factors and predictors of neonatal outcomes among babies born to mothers with PROM.

Materials and Methods: A 3-year retrospective record based descriptive study with 254 neonates delivered at a tertiary care hospital in Coastal Karnataka, India was carried out.

Results: The mean age of mothers was $28.57+/-4.3$ years. Prematurity (39.3\%) followed by hyperbilirubinemia (15.7\%) and respiratory distress $(12.2 \%)$ were the common complications seen, with a neonatal mortality rate of $2.3 \%$. Antenatal complications (24.8\%) and medical issues in the mother (13.7\%) were the most common maternal risk factors associated with PROM. Although 59\% cases delivered vaginally, Emergency Caesarean section was the mode of delivery in $97 \%$ of Caesarean cases. The median duration of latency was 590 minutes [interquartile (IQR) - 390-1,020 mins] with the highest median latency seen for 28-32 weeks of gestation which was 1,380 minutes (IQR: 672.5- 3,386.25 mins). Primiparity [Odds ratio (OR)- 1.99, 95\% Confidence interval (CI)- 1.01-3.91, $\mathrm{p}=0.04$ ] and preterm gestation (OR-2.12, 95\% Cl: 1.08-4.14, $\mathrm{p}=0.025)$ were factors associated with the increased latency period. A latency period $>24$ hours was found to be a significant factor associated with a poor Appearance, Pulse, Grimace, Activity and Respiration (APGAR) score (OR- 5.83, 95\% Cl- 2.85-11.93, p<0.001) and Neonatal Intensive Care Unit (NICU) admission (OR-5.98, 95\% Cl- 2.95-12.14, p<0.001).

Conclusion: PROM is associated with a significant risk of neonatal morbidity and mortality with the most common complications being prematurity and low birth weight. Prolonged PROM increases the risk of neonatal complications. Early recognition and prompt management prevents the delay in intervention and also reduces the risk of neonatal complications.
\end{abstract}

Keywords: Premature rupture of membranes, prematurity, neonatal outcomes, neonatal sepsis, neonatal morbidity

\section{Introduction}

According to a WHO report, 4 million neonates die annually with a global neonatal mortality rate of 23 per 1,000 live births. A million of these are due to neonatal infections. Neonatal sepsis is encountered in 1-10 per 1,000 live births in developed countries and is believed to be three times higher in developing countries (1). Premature rupture of membranes (PROM) is responsible for $5.2 \%$ of neonatal infections (2). 
PROM or pre-labor rupture of membranes refers to the loss of integrity of membranes before the onset of labor, resulting in leakage of amniotic fluid and the establishment of communication between the amniotic cavity and the endocervical canal and vagina. It is a matter of major concern to all obstetricians as well as pediatricians (3).

PROM can present either at term (>37 weeks) or preterm (<37 weeks) (4). The majority (90\%) of PROM occurs in women at term (5). Term PROM is seen in almost $8 \%$ pregnancies (6). Preterm premature rupture of membranes (PPROM) happens in $3-8 \%$ of all pregnancies and is responsible for one third of all preterm births (7). The latency period after PPROM is inversely related to the gestational age at rupture of membrane. Over $90 \%$ of term patients will be in labor within 24 hours of PROM $(4,8,9)$ compared with less than $50 \%$ of preterm patients (8). Hence, at term, PROM is more of a physiological variation rather than a pathological event (10).

Prolonged PROM is seen in $10 \%$ of pregnancies and it is seen when time of delivery from rupture is delayed by more than 24 hours (11). Neonatal complications after PROM are inversely related to the gestational age at the time of rupture and at delivery (4). The fetal and neonatal complications of PPROM include infections and fetal distress due to umbilical cord compression, Respiratory Distress syndrome (RDS), necrotizing enterocolitis, intraventricular hemorrhage, sepsis and pulmonary hypoplasia, and an overall increase in the perinatal morbidity and mortality rate $(4,8)$.

Prompt management in the mother along with early detection of sepsis and aggressive management in neonates significantly improves the neonatal outcome (1). The key to management depends on the accurate assessment of gestational age, likelihood of infection, duration of the latency period and the availability of neonatal intensive care facilities.

The increasing frequency of PROM being encountered in present day scenarios and the lack of sufficient studies in this region justifies the need to carry out this study to focus on the neonatal outcomes in babies born to mothers with PROM along with the factors affecting them.

Definitions used in our study and the selection of the study population:

1. "Premature rupture of membranes or pre-labor rupture of membranes (PROM/PLROM): spontaneous rupture of membranes any time beyond the $28^{\text {th }}$ week of pregnancy but before the onset of labor" (4).
2. "Term premature rupture of membranes (Term PROM): Rupture of membranes after 37 completed weeks of gestation and before the onset of labor" (4).

3. "Preterm premature rupture of membranes (PPROM): Rupture of membranes after the age of viability and before 37 weeks of gestation" (4).

4. "Latency period: the period between initial leakage of fluid and the onset of labor and delivery" (12).

5. "Prolonged rupture of membranes is defined as the rupture of membranes lasting more than 24 hours before the onset of labor" (11).

\section{Objectives of the Study}

1. To determine the neonatal outcomes among babies born to mothers with premature rupture of membranes.

2. To identify the predictors affecting clinical outcomes among these neonates.

3. To compare risks of individual outcomes among neonates according to the latency periods from membrane rupture until the time of delivery.

\section{Materials and Methods}

A cross sectional, descriptive, 3-year retrospective, record based study was carried out in a tertiary care hospital in coastal Karnataka, India, after obtaining a waiver of consent from the institutional ethical clearance committee (approval number: FMMCIEC/CCM/13/2018) using a pretested questionnaire.

- Using the formula:

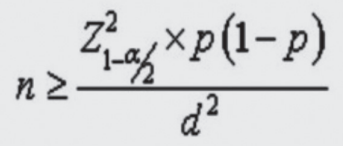

Assuming $p=30 \%$ (13) to be the percentage of perinatal morbidity in babies born to PROM mothers with $\alpha=0.05$ and $80 \%$ power and allowable error $d=6 \%$, we obtain a value for $\mathrm{n}$ of 225 , assuming a non-response rate of $10 \%$, $n$ was rounded up to 250 .

\section{Inclusion Criteria}

All confirmed cases of PROM which occurred at more than 28 weeks of gestation.

\section{Exclusion Criteria}

Neonates with congenital anomalies, multiple pregnancy, pre-eclampsia, eclampsia, polyhydramnios, intrauterine death, antepartum hemorrhage or gestational diabetes mellitus were considered as exclusion criteria. 


\section{Statistical Analysis}

The data collected was entered into Microsoft Excel and analyzed using SPSS 21.0 (IBM, Inc, Chicago, Illinois, USA). Descriptive analysis was performed with mean and standard deviation, median and interquartile range and proportion. An odds ratio (OR) with 95\% confidence intervals (CI) was used to summarize the analytic output, while the $p$ value $<0.05$ was used to assess the statistical significance of an association.

\section{Results}

A total of 254 participants formed the final study group during the 3 -year study period. The mean age of the mothers was $28.57+/-4.3$ years. A total of 115 (45\%) mothers were from rural areas. 43 (17\%) mothers were from families below the poverty line. Three (1.18\%) did not receive essential obstetric care. One hundred thirty-nine (55\%) mothers were multigravida. Antenatal complications (24.8\%) and maternal infections (13.7\%) were the most common risk factors associated with PROM in our study as depicted in Table I. The median duration of latency from rupture to delivery was 590 minutes [interquartile (IQR) - 390-1,020 mins] with duration of latency being highest in the period 28-32 weeks at 1,380 minutes (IQR: 672.5$3,386.25$ mins) and least in the term PROM cases at 510 minutes (IQR-345-852.5 mins). Hundred and fifty (59\%) of deliveries were normal vaginal, and of the 104 (41\%) caesarean sections, only 3 (2.8\%) were elective.

The mean birth weight of babies was $2.63+/-0.6 \mathrm{~kg}$. Ninety-five (37.4\%) were low birth weight babies and $48(18.8 \%)$ required resuscitation at birth. One hundred (39.3\%) were premature, 76 (30\%) required The Neonatal Intensive Care Unit (NICU) care. Hyperbilirubinemia (15.7\%), respiratory distress (12.2\%), and sepsis (6.3\%) were the

Table I. Maternal risk factors associated with premature rupture of membranes

\begin{tabular}{|l|l|l|l|}
\hline No & Maternal risk factors & number (n) & Proportion (\%) \\
\hline 1. & ANC complications & 63 & 24.8 \\
\hline 2. & $\begin{array}{l}\text { Medical issues in the } \\
\text { mother }\end{array}$ & 35 & 13.7 \\
\hline 3. & Maternal infection & 21 & 8.3 \\
\hline 4 & Prior PROM & 18 & 7 \\
\hline 5 & Abnormal USG & 18 & 7 \\
\hline & Total & 155 & 61 \\
\hline $\begin{array}{l}\text { PROM: Premature rupture of membranes, ANC: Absolute neutrophil count, } \\
\text { USG: Ultrasonography }\end{array}$
\end{tabular}

most common neonatal complications as seen in Table II. The mean duration of hospital stay was $6.82+/-4.8$ days. There were $6(2.3 \%)$ neonatal mortalities in our study.

A latency period of more than 24 hours was associated with a poor Appearance, Pulse, Grimace, Activity and Respiration (APGAR) score, (OR-5.83, $\mathrm{p}<0.001$, highly significant) and NICU admission (OR- 5.98, p<0.001, highly significant) as seen in Tables III and IV. Preterm (OR-2.12, $p=0.025$, significant) and primigravida (OR-1.99, $p=0.04$, significant) had a higher chance of having longer latency

Table II. Neonatal outcomes in premature rupture of membranes cases $(n=254)$

\begin{tabular}{|l|l|l|l|}
\hline No & Neonatal outcomes & Number (n) & $\begin{array}{l}\text { Proportion } \\
(\%)\end{array}$ \\
\hline 1. & Prematurity & 100 & 39.3 \\
\hline 2. & Low birth weight & 95 & 37.4 \\
\hline 3. & NICU admission & 76 & 30 \\
\hline 4. & Hyperbilirubinemia & 40 & 15.7 \\
\hline 5. & Respiratory distress & 31 & 12.2 \\
\hline 6. & Neonatal sepsis & 16 & 6.3 \\
\hline 7. & Birth asphyxia & 6 & 2.3 \\
\hline 8. & Necrotizing enterocolitis & 6 & 2.3 \\
\hline 9. & Meningitis & 3 & 1.2 \\
\hline 10. & Death & 6 & 2.3 \\
\hline NICU: Neonatal intensive care unit & & \\
\hline
\end{tabular}

Table III. Association of latency with neonatal appearance, pulse, grimace, activity, and respiration score

\begin{tabular}{|l|l|l|l|}
\hline Duration of latency & \multicolumn{2}{|l|}{ APGAR score } & Total \\
\hline & $>8$ & $<7$ & \\
\hline $\mathbf{2 4 \mathbf { 4 }}$ hrs & $21(50 \%)$ & $21(50 \%)$ & 42 \\
\hline$<\mathbf{2 4}$ hrs & $181(85 \%)$ & $31(15 \%)$ & 212 \\
\hline & $202(80 \%)$ & $52(20 \%)$ & 254 \\
\hline
\end{tabular}

$\mathrm{X}^{2}-26.95, \mathrm{p}-<0.001$, HS. Odds ratio $-5.83,95 \% \mathrm{Cl}-2.85-11.93$, APGAR: Appearance, pulse, grimace, activity, and respiration score, hrs: Hours

Table IV. Effect of latency period on the neonatal intensive care unit admission for various complications

\begin{tabular}{|c|c|c|c|}
\hline \multirow[t]{2}{*}{ Duration of latency } & \multicolumn{2}{|c|}{ NICU admission } & \multirow[t]{2}{*}{ Total } \\
\hline & No & Yes & \\
\hline$>24 \mathrm{hrs}$ & $15(36 \%)$ & $27(64 \%)$ & 42 \\
\hline \multirow[t]{2}{*}{$<24 \mathrm{hrs}$} & $163(77 \%)$ & $49(23 \%)$ & 212 \\
\hline & $178(70 \%)$ & $76(30 \%)$ & 254 \\
\hline
\end{tabular}


Table V. Association of period of gestation with duration of latency

\begin{tabular}{|c|c|c|c|}
\hline \multirow[t]{2}{*}{ Period of gestation } & \multicolumn{2}{|l|}{ Latency } & \multirow[t]{2}{*}{ Total } \\
\hline & $<24$ hrs & $>24 \mathrm{hrs}$ & \\
\hline Pre term & 77 (77\%) & $23(23 \%)$ & 100 \\
\hline \multirow[t]{2}{*}{ Term } & 135 (88\%) & 19 (12\%) & 154 \\
\hline & $212(83 \%)$ & $42(17 \%)$ & 254 \\
\hline
\end{tabular}

Table VI. Duration of latency with parity

\begin{tabular}{|c|c|c|c|}
\hline \multirow[t]{2}{*}{ Parity } & \multicolumn{2}{|l|}{ Latency } & \multirow[t]{2}{*}{ Total } \\
\hline & $<24$ hrs & $>24 \mathrm{hrs}$ & \\
\hline Primi & 90 (78\%) & $25(22 \%)$ & 115 \\
\hline \multirow[t]{2}{*}{ Multi } & $122(88 \%)$ & 17 (12\%) & 139 \\
\hline & $212(83 \%)$ & 42 (17\%) & 254 \\
\hline
\end{tabular}

Table VII. Association of parity with birth weight of the baby

\begin{tabular}{|c|c|c|c|}
\hline \multirow[t]{2}{*}{ Parity } & \multicolumn{2}{|c|}{ Birth weight } & \multirow[t]{2}{*}{ Total } \\
\hline & Normal & LBW & \\
\hline Multi & 75 (54\%) & $64(46 \%)$ & 139 \\
\hline \multirow[t]{2}{*}{ Primi } & $84(73 \%)$ & 31 (27\%) & 115 \\
\hline & 159 (63\%) & $95(37 \%)$ & 254 \\
\hline
\end{tabular}

Table VIII. Association of period of gestation at premature rupture of membranes with birth weight of the baby

\begin{tabular}{|c|c|c|c|}
\hline \multirow[t]{2}{*}{ Period of gestation } & \multicolumn{2}{|c|}{ Birth weight } & \multirow[t]{2}{*}{ Total } \\
\hline & Normal & LBW & \\
\hline Pre term & $23(23 \%)$ & 77 (77\%) & 100 \\
\hline \multirow[t]{2}{*}{ Term } & $136(88 \%)$ & 18 (12\%) & 154 \\
\hline & $159(63 \%)$ & $95(37 \%)$ & 254 \\
\hline
\end{tabular}

as seen in Tables $\mathrm{V}$ and $\mathrm{VI}$. The risk of having low birth weight babies was higher among multigravida (OR-2.31, $p=0.0012$, significant) and preterm gestation (OR-25.29, $\mathrm{p}<0.001$, highly significant) as seen in Tables VII and VIII. Of the 100 preterm deliveries, 54 mothers received antenatal corticosteroids, of which 13 babies (24\%) developed respiratory distress and $3(5.5 \%)$ had birth asphyxia.

\section{Discussion}

Our study included 254 mothers with PROM studied retrospectively for the outcomes in their newborns and those factors predicting these outcomes.
Prematurity (39.3\%) and low birth weight (37\%) were the most common adverse neonatal outcomes seen in our study, which was in disagreement with a study done by Boskabadi $\mathrm{H}$ et al. (14) in Iran, where $67 \%$ were premature. In a study conducted by Ramesh TV et al. (15), 38\% of neonates born to mothers with PROM were premature and $37 \%$ had RDS. Riyami NA et al. (16) in their study concluded RDS to be the most common neonatal complication (79\%) followed by sepsis (50\%). These differences might be due to varied management practices and the time from onset of rupture of the membranes to delivery.

$60 \%$ of the mothers in our study group delivered vaginally, which is similar to two other recent studies on $\operatorname{PROM}(15,17)$.

Idrisa A et al. (18) in their study carried out in Nigeria stressed the importance of the use of intravenous steroids and antibiotics in PROM and concluded that they help to reduce complications and bring about favorable outcomes. Our study revealed that treatment of PROM cases with steroids and antibiotics with or without tocolytics did not show any significant difference in terms of APGAR score or the need for resuscitation in the absence of maternal infection. In our study population, the proportion of babies who developed RDS, whose mothers had received a full course of antenatal corticosteroids (24\%) was almost the same as those who had not received antenatal corticosteroids (26\%), thereby demeaning the importance of the administration of antenatal corticosteroids in preterm labor and this was found to be contradictory to the usual standards of care.

Our study showed that the chances of having a poor APGAR score at birth and requiring NICU admission were significantly higher when the latency period from rupture of membranes until delivery was more than 24 hours.

A study conducted by Jain $\mathrm{N}$ et al. (19) in Jaipur showed $92 \%$ of PROM cases occur between the $32^{\text {nd }}$ and $36^{\text {th }}$ weeks of gestation and also that the latency period tends to be more prolonged in lower gestational ages.

A study conducted on the outcomes of PROM in a tertiary care center in West Bengal by Chakraborty B et al. (20) revealed neonatal mortality in the very preterm group ( $<34$ weeks) to be $10 \%$ as against $5.8 \%$ in preterms (34-37 weeks) and nearly $3 \%$ among term pregnancies (>37 weeks) indicating that gestational age is a major determinant of neonatal survival.

Results of a retrospective Cohort study conducted by Riyami NA et al. (16) in Oman showed a 16\% neonatal mortality rate and revealed neonatal survival was 
significantly associated with gestational age at delivery and not gestational age at the time of rupture.

Neonatal mortality was $2.3 \%$ in our study which was quite similar to a study performed by Boskabadi $\mathrm{H}$ et al. (14).

\section{Study Limitations}

The small sample size and retrospective study design were perceived to be the two most important limitations in our study. A prospective study with a larger sample size would have been better methodologically.

Our study also did not capture those complications in the mother which could have been related with obstetric interventions that could have had a bearing on neonatal outcomes.

Also, there is a paucity of data on the ideal intervention time from membrane rupture to management which could reduce the chances of both prematurity as well as infections, and so could help obstetricians in deciding on the optimal time of management, thereby reducing maternal and neonatal complications.

\section{Conclusion}

PROM is associated with an increased risk of prematurity and neonatal infections. The longer the duration from membrane rupture to delivery, the more the risk of neonatal complications. Preterm PROM is associated with an increased duration of the latency period. Early recognition and prompt management can reduce delays in intervention and also reduce risks of neonatal complications.

\section{Ethics}

Ethics Committee Approval: After obtaining a waiver of consent from the institutional ethical clearance committee (approval number: FMMCIEC/CCM/13/2018) using a pretested questionnaire.

Informed Consent: Informed consent was obtained.

Peer-review: Externally peer-reviewed.

\section{Authorship Contributions}

Concept: S.S., R.A., Design: R.A., Data Collection or Processing: S.S., Analysis or Interpretation: S.S., Literature Search: R.A., Writing: S.S.

Conflict of Interest: No conflict of interest was declared by the authors.

Financial Disclosure: The authors declared that this study received no financial support.

\section{References}

1. Alam MM, Saleem AF, Shaikh AS, Munir O, Qadir M. Neonatal sepsis following prolonged rupture of membranes in a tertiary care hospital in Karachi, Pakistan. J Infect Dev Ctries 2014;8:6773.

2. Ocviyanti D, Wahono WT. Risk factors for neonatal sepsis in pregnant women with premature rupture of the membrane. Journal of Pregnancy 2018:4823404.

3. Larranaga AC, Campo MG, Perez RAF, Ezcurdia GM. Dinoprostone vaginal slow-release system (Propess) compared to expectant management in the active treatment of premature rupture of the membranes at term: impact on maternal and fetal outcomes. Acta Obstet Gynecol Scand 2008; 87:195-200.

4. Dutta DC, Konar H (ed.). DC Dutta's Textbook of Obstetrics including Perinatology and Contraception. 8th ed. Jaypee Brothers Medical Publishers (P) Ltd (New Delhi); 2015:369-70.

5. Zamzami TYY. Prelabor rupture of membranes at term in lowrisk women: induce or wait? Arch Gynecol Obstet 2006;273:27882.

6. Cunningham FG, Leveno KJ, Bloom SL, Williams Obstetrics. 24th ed. McGraw Hill Education 2014;pp.448-9,839-49.

7. Sharma SK, Dey M. Maternal and Neonatal outcomes in cases of premature rupture of membranes beyond 34 weeks of gestation. Int I Reprod Contracept Obstet Gynecol 2017; 6: 13025.

8. Elder MG, Lamont RF, Romero R. Preterm labor. Churchill Livingstone Inc. (New York) 1997; 153-6.

9. Arias F. High risk pregnancy and delivery. 1st ed. Jaypee Brothers (New Delhi); 1990: Ch 4. pp.63.

10. Ozden S, Delikara MN, Avci A, Fiçicioglu C. Intravaginal misoprostol vs. expectant management in premature rupture of membranes with low Bishop scores at term. Int I Gynaecol Obstet Off Organ Int Fed Gynaecol Obstet 2002; 77:109-15.

11. Nagaria T, Diwan C, Jaiswal J. A study on feto-maternal outcome in patients with premature rupture of membranes. Int / Reprod Contracept Obstet Gynecol 2016; 5:4123-27.

12. Gleason CA, Devaskar SU. Avery's diseases of the newborn. 9th ed. Philadelphia: Elsevier Saunders 2012; 144-45,391-92, 540656.

13. Jaiswal AA, Hariharan C, Dewani DKC. Study of maternal and fetal outcomes in premature rupture of membranes in central rural India. Int / Reprod Contracept Obstet Gynecol 2017; 6:1409-12.

14. Boskabadi H, Maamouri G, Mafinejad S. Neonatal complications related with prolonged rupture of membranes. Maced I Med Sci 2011; 4:93-8

15. Ramesh TV, Panigrahi B, Pranaya P, Bindu PH. Outcome of neonates born to mothers with premature rupture of membranes. Int J Contemp Pediatr 2018; 5:1190-4.

16. Riyami NA, Shezawi FA, Ruheli IA, Dughaishi TA, Khabori MA. Perinatal outcome in pregnancies with extreme preterm premature rupture of membranes (mid-trimester PROM). Sultan Qaboos University Med I 2013; 13:51-6. 
17. Kayiga H, Lester F, Amuge PM, Byamugisha I, Autry AM. Impact of mode of delivery on pregnancy outcomes in women with premature rupture of membranes after 28 weeks of gestation in a low-resource setting: A prospective cohort study. PLoSONE 2018; 13:e0190388.

18. Idrisa A, Pius S, Bukar M. Maternal and neonatal outcomes in premature rupture of membranes at university of Maiduguri teaching hospital, Maiduguri, North-Eastern Nigeria. Trop I Obstet Gynaecol 2019; 36:15-20.
19. Jain $N$, Reena $P$, Banerjee KP, Lata R, Gupta D. A study of perinatal outcome in premature rupture of membrane. Sch I App Med Sci 2017; 5:1391-5.

20. Chakraborty B, Mandal T, Chakraborty S. Outcome of prelabor rupture of membranes in a tertiary care centre in West Bengal. Indian Journal of Clinical Practice 2013; 24. 